\title{
David Hull
}

\author{
Mauro Pontani ${ }^{1}$. Jason L. Speyer ${ }^{2}$
}

Received: 7 September 2021 / Accepted: 7 September 2021 / Published online: 31 October 2021

○ The Author(s), under exclusive licence to Springer Science+Business Media, LLC, part of Springer Nature 2021

In January 2019, Professor David Hull stepped down from his role of Editor-in-Chief of the Journal of Optimization Theory and Applications, after 9 years of invaluable service.

Professor Hull became Editor-in-Chief of the Journal of Optimization Theory and Applications in 2010, when Angelo Miele, founder of the Journal and Editor-in-Chief for over 40 years, retired.

In his career, Professor Hull investigated a variety of topics in theoretical and numerical optimization, with special focus on aerospace applications. His early contributions date back to the 1960s, when he studied airfoil shape optimization for minimum drag in hypersonic flight. In the subsequent decade, he proposed the generalized perturbation method for solving two-point boundary value problems and applied it to optimizing the descent path of the space shuttle. Hull was a pioneer in the conversion of optimal control problems into parameter optimization problems. This numerical methodology was investigated and employed extensively in the succeeding years, by many researchers. He applied his techniques to the calculation of optimal atmospheric trajectories including those of launch vehicles, reentry vehicles, and missiles. In the 1980s, Professor Hull provided fundamental contributions on three challenging aerospace topics: (a) optimal aeroassisted orbital transfer maneuvers, (b) guidance and navigation techniques for homing missiles, and (c) guidance along descent paths for maneuvering reentry vehicles.

Later on, he concentrated on more theoretical aspects of optimal control theory. One of his greatest achievements is in the clarification of the use of differentials in optimization and perturbation theory. The use of differentials has made it possible to unify all the theories of optimal control, with a special focus on aerospace applications. This led to the development of the second variation for free-final-time optimal control problems, illuminating the relation between time-constant and time-free variations.

$\bowtie$ Mauro Pontani

mauro.pontani@uniroma1.it

1 Department of Astronautical, Electrical, and Energy Engineering, Sapienza Università di Roma, Rome, Italy

2 Department of Mechanical and Aerospace Engineering, University of California, Los Angeles, CA, USA 
Together with the sufficient conditions for a minimum, these analytical achievements were fundamental ingredients for the development of neighboring optimal guidance. In the same period, he proved effectiveness of error compensation both in improving the performance of approximate optimal control and in neighboring optimal control. Professor Hull investigated also singular optimal control problems, with special focus on variable-thrust subarcs of rocket trajectories. Most recently, he did extensive research on real-time guidance for lunar ascent trajectories.

Along with these investigations, Professor Hull wrote his book Optimal Control Theory for Applications, which immediately stood out for its style and clarity, and in fact rapidly became a reference book for both researchers and practitioners. The second book he wrote, Fundamentals of Airplane Flight Mechanics, exhibits the same remarkable features, although the focus is on a more practical subject.

The scientific accomplishments of Professor Hull in analytical and numerical optimization methods, as well as in aerospace trajectory optimization and guidance, remain in the archival literature of the twentieth and twenty-first century, as a testament of his approach, efforts, and results in optimization theory and applications, which are outstanding, both in breadth and in depth.

After several years of industrial experience (including five years at Boeing Scientific Research Laboratories), in 1966 Professor Hull joined the Cockrell School of Engineering at the University of Texas at Austin. After nearly 50 years of service, he retired in 2015, when he was appointed Professor Emeritus. Over the years, he was the principal investigator of several research projects, and received numerous awards for teaching and research, including the Cockrell School of Engineering's Departmental Teaching Award and Faculty Excellence Award and the AAS/AIAA Space Flight Mechanics Conference Best Paper Award. He was named Fellow of the American Astronautical Society in 2005.

Professor Hull is still fully involved in his research activity. After his retirement as an Editor-in-Chief, the Journal of Optimization Theory and Applications looks forward to many years of cooperation with him, either as a contributing author or as an advisor.

Publisher's Note Springer Nature remains neutral with regard to jurisdictional claims in published maps and institutional affiliations. 